\title{
O ENSINO REMOTO COM O LÚDICO DURANTE A PANDEMIA DA COVID-19: DESAFIOS E APRENDIZAGENS
}

\section{THE REMOTE LUDIC TEACHING DURING THE COVID-19 PANDEMIC: CHALLENGES AND LEARNINGS}

\author{
Rosycléa Dantas ${ }^{1}$ \\ Elaine Silva ${ }^{2}$
}

\begin{abstract}
RESUMO: No Brasil, assim como em muitos países no mundo, escolas foram fechadas como parte das medidas de prevenção da COVID-19. Nesse cenário, muitas escolas adotaram o ensino remoto de emergência (HODGES et al., 2020) e os professores e alunos precisaram se adaptar ao ensino online. No campo da Linguística Aplicada (MOITA LOPES, 2015) e levando em consideração esses aspectos, esta pesquisa tem como principal objetivo investigar como dois professores de língua inglesa compreendem o trabalho com o lúdico no ensino remoto 3 . Para tanto, utilizamos como suporte teórico os estudos recentes acerca do ensino remoto (ARRUDA, 2020; CORDEIRO, 2020; HODGES et al., 2020) e sobre ludicidade e educação (NOGUEIRA 2008; SANTOS, 2010; e SILVA; FANTINELLI, 2019). Os dados foram gerados por meio de entrevistas - via aplicativo de WhatsApp com dois professores de língua inglesa que atuam em escolas públicas de Alagoas, Brasil. A análise qualitativa evidencia os desafios e aprendizagens que os professores experienciaram com a utilização do lúdico no ensino remoto, durante a pandemia da COVID-19. As implicações são apresentadas no campo da formação docente, com a adoção de saberes sobre tecnologias digitais e ensino online.
\end{abstract}

PALAVRAS-CHAVE: Língua inglesa. Ensino remoto. Lúdico. Pandemia da COVID-19.

ABSTRACT: In Brazil, as in many countries worldwide, schools were closed as part of the COVID-19 prevention measures. In this scenario, many schools have adopted emergency remote teaching (HODGES et al., 2020) and teachers and students have had to adapt to online teaching. In the field of Applied Linguistics (MOITA LOPES, 2015) and taking these aspects into consideration, the main goal of this study is to investigate how two English language teachers understand the ludic teaching in the context of remote teaching. For this purpose, we used as theoretical framework the recent studies on remote teaching (ARRUDA, 2020; CORDEIRO, 2020; HODGES et al., 2020) and on playfulness and education (NOGUEIRA 2008; SANTOS, 2010; and SILVA; FANTINELLI, 2019). The data generation was carried out through interviews - via WhatsApp application - with two English teachers who work in public schools in Alagoas, Brazil. The qualitative analysis shows the challenges and learnings experienced by teachers with regard to playfulness in remote teaching, during the COVID-19 pandemic. Implications are discussed in the field of teacher education, concerned with the adoption of knowledge about digital technologies and online teaching.

KEYWORDS: English language. Remote teaching. Ludic. COVID-19 pandemic.

\section{Considerações iniciais}

No ano de 2020 passamos por mudanças no cenário mundial, decorrentes da pandemia do novo Coronavírus (SARS-CoV-2), causador da COVID-19. Em fevereiro de 2020, o Brasil confirmou o primeiro caso positivo de coronavírus e, desde então, passamos a enfrentar uma nova realidade, com medidas de proteção que envolvem, principalmente, uso de máscara,

\footnotetext{
${ }^{1}$ Doutora em Linguística Aplicada pela Universidade Federal da Paraíba (UFPB). Professora de Língua Inglesa da Faculdade de Letras da Universidade Federal de Alagoas. E-mail: rosyclea.dantas.silva@,fale.ufal.br.

${ }^{2}$ Graduada em Letras-Inglês pela Universidade Federal de Alagoas. E:mail: laininha naine@ $@$ hotmail.com.

${ }^{3}$ Este estudo é um recorte da pesquisa de Monografia intitulada: Ludicidade no ensino remoto: desafios e aprendizagens no ensino da língua inglesa durante a pandemia da Covid-19, da autora Elaine Silva, sob a orientação da professora Dra. Rosycléa Dantas.
} 
higiene das mãos e distanciamento social. Desse modo, foi necessário repensar a dinâmica escolar, uma vez que as aulas presenciais foram suspensas com o intuito de minimizar a transmissão do vírus e, consequentemente, prevenir a COVID-19. Assim, em muitos contextos, professores e alunos passaram a interagir e a criar espaços de ensino-aprendizagem de maneira remota (ARRUDA, 2020; CORDEIRO, 2020; BASTOS; LIMA, 2020), o que se configurou como um desafio para todos os envolvidos.

Dentre os desafios enfrentados pelos alunos, as limitações de acesso à internet e a tecnologias digitais (BRASIL, 2020) fazem parte da nossa realidade social, dificultando o desenvolvimento de uma educação remota acessível para todos. No contexto docente, destacamos a limitação de saberes relacionados à utilização do espaço online como ferramenta educacional e ao domínio dos recursos tecnológicos digitais, tendo em vista que eles não faziam parte da rotina de muitos professores no ensino presencial.

Com essas reflexões, e compreendendo, no âmbito da Linguística Aplicada, que a produção do conhecimento necessita levar em consideração "a complexidade das práticas em que vivemos" (MOITA LOPES, 2015, p. 21), como forma de criar "inteligibilidade", concordamos com Bastos e Lima (2020, p.76), ao afirmarem que "avaliar a oferta do ensino remoto em tempos de isolamento social se torna tão emergencial quanto sua própria oferta". Precisamos investigar e compreender como a educação está sendo (re)construída no contexto remoto. Nesta pesquisa, buscamos contribuir com essa compreensão a partir de discussões acerca do trabalho de professores de língua inglesa com a ludicidade, no âmbito do ensino remoto. Ouvimos dois professores que atuam no Ensino Fundamental, em escolas públicas de Alagoas, e nos propomos a responder às seguintes questões de pesquisa:

1. Quais os desafios apresentados por dois professores de língua inglesa no trabalho com a ludicidade no ensino remoto?

2. Como dois professores de língua inglesa descrevem as aprendizagens construídas a partir da experiência no ensino remoto e do trabalho com o lúdico.

Partindo do pressuposto de que, mesmo sem preparação adequada, os professores foram solicitados a ministrarem aulas de maneira remota, em meio a uma pandemia, e, por isso, experienciam desafios e aprendizagens, buscamos atingir o objetivo deste trabalho que é investigar como dois professores de língua inglesa compreendem o trabalho com o lúdico no ensino remoto.

A fim de responder nossas questões de pesquisa, buscamos suporte teórico nos estudos recentes sobre o ensino remoto (ARRUDA, 2020; CORDEIRO, 2020; GARCIA et al., 2020; HODGES et al., 2020; e SILVA et al., 2020) e nas pesquisas sobre ludicidade e a educação (NOGUEIRA, 2008; SANTANNA; NASCIMENTO, 2011; SANTOS，2010; SILVA; FANTINELLI, 2019).

Como justificativa para esse estudo, entendemos que o trabalho com o lúdico, no contexto de educação online e em período de isolamento social, ganha novas formas e pode contribuir para a motivação e o interesse dos alunos pela aprendizagem da língua inglesa. Assim, defendemos que os resultados e discussões da presente pesquisa podem auxiliar em uma maior compreensão a respeito da importância do lúdico no atual contexto do ensino remoto e no ensino online de modo geral. Também compreendemos que a relevância desta pesquisa remete a discussões sobre o trabalho e a formação docente com vistas a valorizar a fala dos professores sobre seu fazer pedagógico e a destacar a necessidade de uma formação docente que contemple o contexto online e as tecnologias digitais.

Nessa perspectiva, organizamos o estudo da seguinte maneira. Inicialmente, discutiremos sobre o ensino remoto em tempos de pandemia. Em um segundo momento, refletiremos acerca do lúdico no contexto educacional. Posteriormente, apresentamos o percurso metodológico realizado ao longo da presente pesquisa. Por último, realizaremos a 
Volume 16 - Número 1 - jan/jul de 2021

análise dos dados com base no referencial teórico discutido. Após a análise, apresentaremos as considerações finais do estudo e as referências citadas no texto.

Desse modo, apresentamos a seguir a discussão teórica que orienta esta pesquisa.

\section{Ensino remoto em tempos de pandemia}

No cenário de pandemia do novo Coronavírus, a escola passou a ser um dos espaços mais temidos pelo risco da transmissão. Para Arruda (2020, p. 259), há mais riscos no ambiente escolar pelo fato de que "cria vínculos entre aqueles que são menos propensos aos sintomas graves da doença (jovens) a todos os demais que podem ser até mortalmente propensos". Além desse aspecto, o autor aponta que

A escola é um dos espaços sociais em que há maiores trocas e mobilidades de sujeitos de diferentes faixas etárias, portanto, representa espaço de maior probabilidade de contaminação em massa - o que indica ser um dos últimos espaços a ser reaberto em países que controlaram minimamente a taxa de contaminação do novo coronavírus. (ARRUDA, 2020, p. 259)

Como espaços de maior probabilidade de infecção pelo coronavírus, as instituições de ensino precisaram fechar suas portas. Por conseguinte, em 28 de abril de 2020, o Conselho Nacional de Educação - CNE - (BRASIL, 2020) publicou um parecer orientando a reorganização do calendário escolar e a possibilidade de cômputo de atividades não presenciais para cumprimento de carga horária, durante o período de isolamento social, decorrente da pandemia do novo coronavírus.

Nesse cenário, instituições escolares começaram a buscar maneiras de seguir com as atividades, dentre elas: aulas via rádio e televisão, entrega de materiais impressos para alunos sem acesso à internet e aulas por meio de plataformas digitais. $\mathrm{O}$ ensino remoto de emergência (HODGES et al., 2020) foi adotado por muitas instituições, dentre elas as escolas de educação básica em que atuam os colaboradores desta pesquisa.

No debate sobre ensino remoto, pesquisadores como Arruda (2020), Garcia et al. (2020) e Hodges et al. (2020) afirmam que o ensino remoto não é sinônimo de educação a distância (EAD), embora estejam relacionados ao uso de tecnologias digitais. Sobre a educação a distância, Arruda (2020), a partir das reflexões de Maia e Mattar (2008), discute que a EaD "envolve planejamento anterior, consideração sobre perfil de aluno e docente, desenvolvimento a médio e longo prazo de estratégias de ensino e aprendizagem que levem em consideração as dimensões síncronas e assíncronas da EaD” (ARRUDA, 2020, p. 265).

A educação a distância envolve um processo de planejamento diante das especificidades do contexto virtual, esse é um aspecto fundamental para a distinção entre EAD e ensino remoto. $\mathrm{Na}$ compreensão de Hodges et al. (2020, p. 6), "ao contrário das experiências planejadas desde o início e projetadas para serem online", o ensino remoto de emergência, como definido pelos autores, "é uma mudança temporária para um modo de ensino alternativo devido a circunstâncias de crise". É uma possibilidade de fazer educação diante do isolamento social, de modo que, quando a crise diminuir ou acabar, voltarão os métodos de ensino utilizados anteriormente, na modalidade de ensino presencial. Os autores pontuam que o objetivo, nessas circunstâncias, não é (re)criar um sistema educacional online, "mas fornecer acesso temporário a suportes e conteúdos educacionais de maneira rápida, fácil de configurar e confiável, durante uma emergência ou crise" (HODGES et al., 2020, p. 6).

É nessa perspectiva de Hodges et al. (2020) que compreendemos o ensino remoto. Porém, entendemos que os modos de fazer educação utilizados no ensino remoto de emergência são provenientes da EAD e do ensino presencial e, assim, acreditamos que os saberes 
construídos remotamente por docentes, alunos, gestores e demais membros da comunidade escolar também irão contribuir para a EAD e o ensino presencial, uma vez que esses saberes começam a compor a maneira como ensinamos, aprendemos e pensamos o fazer educativo.

Ao discutir sobre os professores no ensino remoto, Hodges et al. (2020, p. 6) afirmam que "é impossível que, de um dia para o outro, todos os membros do corpo docente se tornem especialistas no ensino e aprendizagem online". Essa afirmação ressalta que muitos professores estão aprendendo a trabalhar no contexto do ensino remoto e, portanto, erros e acertos, idas e vindas fazem parte do processo.

A maioria dos recursos tecnológicos utilizados no contexto de uma educação digital não fazem/faziam parte dos saberes docentes de muitos professores do ensino presencial e, por isso, como discute Garcia et al. (2020), existe, por parte de alguns, uma negativa em se considerar as tecnologias digitais como elementos de fazer educação. Apesar das negativas, vários professores tiveram que encarar o desafio de trabalhar com ferramentas digitais, a exemplo dos docentes colaboradores desta pesquisa.

A importância das tecnologias digitais era ressaltada antes da pandemia da COVID-19, como pontuado por Valente $(2007$, p. 2) ao afirmar que "a presença das tecnologias digitais em nossa cultura contemporânea cria novas possibilidades de expressão e comunicação". Com a pandemia, o debate sobre as tecnologias ficou mais evidente e necessário, sendo uma das questões centrais a desigualdade de acesso à educação no contexto digital. Silva et al. (2020, p.40) destacam que no Brasil "o número de jovens que não possuem acesso à internet é bem superior, o que gera desigualdades sociais entre ricos e os mais vulneráveis".

Nessa linha de reflexão, o CNE (BRASIL, 2020, p. 3) orienta que as instituições de ensino básico e superior considerem "propostas que não aumentem a desigualdade ao mesmo tempo em que utilizem a oportunidade trazida por novas tecnologias digitais de informação e comunicação", uma vez que existem diferenças "em relação às condições de acesso ao mundo digital por parte dos estudantes e de suas famílias" (BRASIL, 2020, p. 3). Assim, entendemos que nem todos os alunos podem acompanhar as aulas em plataformas digitais e, por isso, a necessidade de propostas que busquem contemplar diferentes formas de acesso à educação.

Para Cordeiro (2020. p. 3), o desafio diante das desigualdades sociais é enorme, "haja vista que nem todas as crianças têm computador ou tablet conectados à internet. Contudo, o ensino remoto ainda é a melhor saída para minimizar o atraso no retorno às aulas presenciais". A autora destaca, ainda, que assim como grande parte dos alunos não disponibilizam de equipamentos e internet, muitos professores também não possuem os recursos necessários em casa, para prepararem uma educação online de forma eficiente.

Nesse contexto, Joye et al. (2020) ressaltam que com a pandemia da COVID-19, veio à tona um problema enfrentado há muito tempo: a falta de formação docente referente o uso de tecnologias digitais para a educação. Desse modo, as autoras descrevem que desde o início das aulas remotas, muitos professores passaram a utilizar diversas plataformas e aplicativos com o intuito de alcançar todos os seus alunos, através de lives, encontros online ou até mesmo aulas disponíveis no Youtube, mas que, em algumas situações, não havia formação para os professores utilizarem as ferramentas e/ou prepararem os materiais, o que existia era "a imposição do uso de tecnologias digitais para essa situação, sem a devida orientação ou formação para os docentes" (JOYE et al., 2020, p. 13). Com essa reflexão, acreditamos que investir na formação docente inicial e continuada, em uma formação com e para o uso de tecnologias digitais, pode contribuir significativamente para a construção de saberes que ampliem os modos de fazer educação online e, também, presencial.

Além da formação docente, Cordeiro (2020, p. 3) destaca que "as ferramentas remotas precisam ter parâmetros de qualidade, para que tenham maior eficácia". Sob esse prisma, Hodges et al. (2020, p. 5) afirma que desenvolver parâmetros de qualidade, assim como elaborar um sistema de suporte eficaz para os alunos "leva tempo para ser identificado e construído". 
Mesmo diante das desigualdades, da falta de recursos e de formação, muitos professores tiveram que se adaptar ao ensino remoto (CORDEIRO, 2020; BASTOS; LIMA, 2020) e os que tinham pouco ou nenhum contato com a tecnologia precisaram encarar o desafio, planejando "aulas mediadas por telas junto a seus coordenadores pedagógicos, ao mesmo tempo em que descobrem sobre o funcionamento de ferramentas tecnológicas" (CORDEIRO, 2020, p. 6).

Segundo Cordeiro (2020, p. 6), é evidente que com o ensino remoto, surgiram novas situações até então não comuns nas aulas presenciais, "como problemas de conexão e engajamento dos alunos à distância". Houve insegurança e desconforto por parte dos professores, os quais não estavam habituados em ministrar aulas online, preparar o material para ser disponibilizado digitalmente, gravar vídeos e interagir com vários alunos ao mesmo tempo nas redes sociais. Porém, como discute a pesquisadora, "em contrapartida muitos professores se destacaram no desenvolvimento de suas atividades assim como se tornaram parceiros e inspiração para outros educadores" (CORDEIRO, 2020, p. 7).

Com essa reflexão, concordamos com a autora ao ressaltar que as adaptações para o ensino, por meio do espaço virtual e do uso de tecnologias digitais, trouxeram vários desafios, dentre eles "reaprender a ensinar e reaprender a aprender" (CORDEIRO, 2020, p. 6). Um dos processos de (re)aprendizagem, foco desta pesquisa, é o trabalho com o lúdico no ensino remoto. Por isso, apresentamos uma breve reflexão sobre essa temática na próxima seção.

\section{O lúdico e os processos de ensino-aprendizagem}

De acordo com Silva e Fantinelli (2019), a palavra "lúdico" origina do latim ludus que significa jogos infantis ou recreação. Os autores ressaltam, também, que o conceito de lúdico está associado ao ato de brincar, algo inerente ao ser humano. Segundo Barbosa (2010, p. 12), "através do brincar a criança expressa sua cultura, o diálogo com suas experiências, os costumes e convívio social". Assim, o ato de brincar se configura como espaço de aprendizagem dentro e fora da sala de aula. Santos (2010, p. 27) preconiza que "o brincar e o educar são atividades complexas em que devem ser estudadas as relações, pois de uma forma ou outra auxiliam no desenvolvimento humano". Nessa perspectiva, o lúdico também está associado aos processos de ensino e de aprendizagem.

Santanna e Nascimento (2011) discutem que desde a antiguidade o lúdico faz parte do nosso dia a dia, adequando-se ao contexto histórico de cada época, estando presente até os dias atuais. Mencionando o exemplo da herança histórica e cultural brasileira, os autores destacam que os índios, ao passarem suas tradições para seus filhos, já faziam uso de maneiras lúdicas ao ensinarem a caça e a pesca. Os pesquisadores ressaltam, ainda, que além de diversão, as atividades lúdicas utilizadas passaram a fazer parte do processo de desenvolvimento dos indivíduos, inclusive no que diz respeito à socialização, já que envolve o desenvolvimento de inúmeras habilidades. Sob esse prisma, Nogueira (2008) afirma que, além de explorar a criatividade dos alunos, o lúdico auxilia na construção da autoestima destes, propiciando interação, promovendo cooperação, facilitando a aprendizagem e fazendo com que a sala de aula se torne um ambiente favorável para a aprendizagem.

Essa discussão retoma as reflexões de Rolim et al. (2008, p. 177), ao afirmar que na brincadeira "reside a base daquilo que, mais tarde, permitirá à criança aprendizagens mais elaboradas. O lúdico torna-se, assim, uma proposta educacional para o enfrentamento das dificuldades no processo ensino-aprendizagem”. Nessa mesma linha de reflexão, Nogueira (2008) destaca que:

O desenvolvimento lúdico além de facilitar a aprendizagem, contribui para o desenvolvimento pessoal, social e cultural, colabora para uma boa saúde 
Volume 16 - Número 1 - jan/jul de 2021

mental, prepara para um estado interior fértil, facilita os processos de socialização, comunicação, expressão e consequentemente a curiosidade e a construção do conhecimento. (NOGUEIRA, 2008, p.5)

O lúdico como ferramenta para a construção do conhecimento reforça seu valor como recurso pedagógico. Nesse sentido, Nogueira (2008) discute que o ensino lúdico contribui para a participação ativa dos alunos no processo educativo e, por conseguinte, para a formação da sua cidadania. O lúdico desperta a motivação dos alunos dentro da sala de aula (NOGUEIRA, 2008), podendo gerar fatores positivos para o ensino-aprendizagem, como "criatividade, desinibição, espontaneidade, socialização, entre outros" (PESSOLANO; DALLA CORTE, 2001, p. 4). Nessa linha de reflexão, Michelon (2003) discute que muitos professores analisam a possibilidade de realizar ações lúdicas para motivar e engajar os alunos.

Nogueira (2008) postula, também, que cabe ao professor pesquisar e utilizar atividades lúdicas que possam motivar os alunos, para que eles possam assimilar e internalizar o conteúdo estudado, e assim produzir suas próprias formas de aprender. A autora defende que:

\begin{abstract}
Através da ludicidade o aluno forma conceitos, estabelece relações sociais com o grupo ao qual está inserido, estimula seu raciocínio no desenvolvimento que exigem reflexão, vai se socializando, se sente mais a vontade, mais motivado, aprende e consequentemente melhora seu desempenho. Mas, vale salientar que tais atividades só terão o seu devido valor, se o professor estiver preparado para realizá-las. (NOGUEIRA, 2008, p. 3)
\end{abstract}

No âmbito desta pesquisa, a reflexão de Nogueira (2008) sobre a preparação e o conhecimento do professor para realizar atividades lúdicas efetivas, nos chama a atenção para o fato de que, como discutimos anteriormente, a maioria dos professores que atuavam no ensino presencial, não foram preparados para desenvolver atividades lúdicas em salas virtuais. E, por isso, a necessidade de investigar tais atividades, considerando o contexto social em que estão inseridas.

Nogueira (2008) pontua, igualmente, que o lúdico não só integra dimensões da personalidade (afetiva, motora e cognitiva), como também desperta o esforço voluntário e o prazer em aprender. Ao enfrentarmos uma pandemia que chegou a provocar um número diário de mortes de mais de três mil e oitocentos brasileiros, entendemos que professores e alunos precisam de atividades que possam motivar seu engajamento, esforço e prazer em ensinar e aprender.

\title{
4 Percurso metodológico
}

Utilizamos uma pesquisa de natureza qualitativa, a qual, de acordo com Zanella (2013) busca a descoberta, a identificação e a descrição detalhada e aprofundada de questões sociais, dialogando com as reflexões de Moita Lopes (2015) ao afirmar que a pesquisa em Linguística Aplicada precisa ser responsiva aos problemas sociais. Além disso, existe uma preocupação em identificar um fenômeno com base "na perspectiva dos sujeitos participantes da pesquisa" (ZANELLA, 2013, p. 99). No presente estudo, realizamos uma análise a partir da perspectiva dos professores, isto é, da interpretação que eles fazem da sua atividade educacional.

Como participantes da pesquisa, contamos com dois professores de língua inglesa do ensino fundamental, os quais atuam em turmas do $6^{\circ}$ ao $9^{\circ}$ ano. Os colaboradores trabalham nas redes municipal e estadual de Alagoas e, com o início da pandemia do novo Coronavírus, estão atuando no ensino remoto. Ambos optaram por não utilizar pseudônimos, logo serão identificados por seus próprios nomes. Cícero e Ricardo são professores com mais de nove anos 
de atuação docente e, no momento da geração de dados, estavam atuando no ensino remoto durante sete meses, com uma média de quinze turmas e trinta alunos por turma.

Os convites para as entrevistas foram realizados através de conversas no aplicativo de mensagens WhatsApp. Após a explicação do objetivo da pesquisa, ambos os professores aceitaram prontamente e assinaram o termo de consentimento livre e esclarecimento. $\mathrm{O}$ aceite dos professores foi o primeiro passo para a geração dos dados, que descrevemos a seguir.

Seguindo as orientações de distanciamento social para prevenção da Covid-19 e, portanto, diante da impossibilidade de um encontro presencial com os colaboradores, a entrevista, nosso instrumento de geração de dados, foi realizada de maneira virtual, por meio do aplicativo WhatsApp. O uso do WhatsApp foi uma escolha dos participantes, pois consideraram ser mais acessível e ágil para a realização da entrevista.

Sobre a relevância da entrevista como instrumento de geração de dados, Bastos e Santos (2013) ressaltam que:

ao contarem suas experiências, os entrevistados realizam o trabalho de reorganizá-las, conferindo atualidade a eventos ocorridos há algumas horas ou há muitos anos do momento da narração. $\mathrm{O}$ ato de narrar constitui, assim, um retorno à experiência [...] ao contar sua experiência, o narrador possibilita a si e aos que estão a seu redor pensarem sobre ela. (BASTOS; SANTOS, 2013, p.30)

Compreendemos que a entrevista possibilita aos participantes "um retorno à experiência" (BASTOS; SANTOS, 2013, p. 30), com um olhar interpretativo. Como ressaltam os autores, entrevistados e pesquisadores vivem a experiência de refletir sobre o que está sendo narrado, o que faz da entrevista um espaço de aprendizagem para ambos.

O cuidado de ouvir e considerar as escolhas dos participantes foi algo que prezamos durante toda a geração de dados. Nos preocupamos em deixar os colaboradores confortáveis quanto ao ambiente virtual de interação e, por isso, além da escolha do espaço virtual, as entrevistas foram realizadas em dias e horários estipulados pelos professores, de acordo com a disponibilidade de cada um. As entrevistas com Cícero e Ricardo foram realizadas no turno da tarde, nos dias 05 e 04 de outubro de 2020, respectivamente. A duração da gravação foi de 1 hora e 17 minutos com o professor Cícero e de 1 hora e 58 minutos com o professor Ricardo.

Após a entrevista, realizamos a transcrição dos áudios. Segundo Bastos e Santos (2013, p. 30), a transcrição se constitui “na 'fixação' da narrativa”. Os autores pontuam, igualmente, que "a transcrição, também, é uma seleção. Diferentes formas de transcrição carregam e dão suporte a diferentes interpretações e posicionamentos teóricos" (BASTOS; SANTOS, 2013, p. 31). Diante do objetivo da presente pesquisa, optamos por realizar uma transcrição "ipsis litteris' da fala dos professores, sem a utilização de uma notação específica para transcrição.

Sobre os procedimentos de análise dos dados, Bastos e Santos (2013) nos permitem compreender que a análise dos dados é a construção de uma narrativa que varia de acordo com as escolhas do pesquisador, com seus valores e posicionamentos políticos, ou seja, é uma possibilidade de leitura. Assim, na nossa interpretação dos dados, nos filiamos ao modelo de análise sóciodiscursiva proposto em Bronckart (2012 [1999]), mais especificamente a categoria de análise do conteúdo temático, que faz parte da infraestrutura geral do texto. O conteúdo temático de um texto é "[...] o conjunto das informações que nele são explicitamente apresentadas" (BRONCKART, 2012 [1999], p. 97), variando em função do contexto e da experiência do agente produtor, em nossa pesquisa, dos professores de língua inglesa no cenário de aulas remotas em situação de pandemia. Assim, organizamos os conteúdos temáticos mais recorrentes nas falas dos colaboradores em duas categorias, a saber: i. desafios da ludicidade no ensino remoto; e ii. aprendizagens durante o ensino remoto. Neste artigo, as categorias são 
construídas a partir de 13 excertos de falas dos professores e buscam atender aos objetivos da pesquisa.

Com a apresentação do percurso da pesquisa, conduzimos nossas discussões para a análise dos dados.

\section{Ensino remoto e ludicidade: a voz dos professores}

$\mathrm{Na}$ presente seção analisamos como os nossos colaboradores, que estão atuando no ensino remoto, interpretam suas atividades. Conforme apresentamos nos procedimentos de análise, organizamos os temas mais recorrentes nas falas dos professores em duas categorias: desafios da ludicidade no ensino remoto e aprendizagens durante o ensino remoto.

\subsection{Desafios da ludicidade no ensino remoto}

Conforme discutimos anteriormente, diante da impossibilidade das aulas presenciais, as instituições escolares começaram a buscar maneiras de seguir com as atividades, desse modo, houve a implantação do ensino remoto de emergência (HODGES et al., 2020). Nossos colaboradores, quando questionados sobre o mês de início das aulas remotas, relataram o desenvolvimento de atividades online logo nos meses iniciais da pandemia no Brasil: o professor Cícero, no mês de março e o professor Ricardo, no mês de abril.

Nesse cenário, consideramos importante destacar que, mesmo diante das inúmeras incertezas provenientes da educação em um contexto virtual, em meio à pandemia, alunos e professores iniciaram suas atividades. Assim, entendemos que eles não tiveram tempo suficiente para um planejamento mais elaborado e pensado para ser executado no contexto online, o que reforça as discussões de Hodges et al. (2020) sobre o ensino remoto como uma solução emergencial.

No âmbito dessa discussão, iniciamos com as falas dos nossos colaboradores sobre a relevância do lúdico para a motivação (NOGUEIRA, 2008) e compreensão da língua inglesa no ensino remoto:

\section{Excerto 01 - Professor Cícero}

O lúdico é algo imprescindível e os alunos amam, tanto que ficam ansiosos e no início das aulas já questionam se durante a aula vai ter música. Desse modo, hoje em dia eu não vejo o ensino, principalmente de inglês, sem essa parte lúdica que chama muita atenção do aluno. [grifo nosso].

\section{Excerto 02 - Professor Ricardo}

O meu método de levar o conhecimento da língua inglesa ao aluno é através do lúdico. Eu aprendi dessa maneira e sei que dá muito resultado. As imagens na língua inglesa ajuda muito ao aluno a memorizar, entender, e compreender muita coisa, como vocabulário e expressões, entre outros [...] Então comparando a minha aula presencial, onde eu utilizo o lúdico e inúmeros recursos visuais, com o lúdico no ensino remoto, eu tenho o cuidado de não deixar a minha aula monótona. Então eu procuro inovar, para que não se torne uma aula onde só eu fique falando e os alunos não participem. Então eu sempre busco trazer situações que possam chamar a atenção deles. [grifo nosso].

Esses excertos corroboram as reflexões de Nogueira (2008), sobre o papel do lúdico na motivação dos alunos. Ambos os professores relatam utilizar o lúdico no ensino remoto, destacando que ele é imprescindível e ajuda muito no processo de ensino aprendizagem da língua inglesa. Cícero e Ricardo pontuam que o lúdico chama a atenção dos alunos, despertando mais questionamentos, promovendo aulas menos monótonas e com mais participação. Nesse 
sentido, reforçamos a necessidade de métodos e materiais que possam promover a motivação dos alunos, pois a utilização de ações lúdicas engaja os alunos (NOGUEIRA, 2008). Apesar de compreenderem a relevância, os professores sentem dificuldades para utilizar o lúdico nas aulas online.

\section{Excerto 03 - Professor Ricardo}

A escassez de equipamentos, como por exemplo, um estúdio, para que pudéssemos ter uma boa iluminação, e usar todos os recursos audiovisuais que temos disponíveis. Uma lousa disponível para explicação. Infelizmente alguns professores não têm esses recursos, não tem um lugar disponível só para as aulas, não tem uma internet de boa qualidade. Então a condição financeira do professor atrapalha muito. Então o maior empecilho é não poder mostrar o lúdico de uma forma mais ampla (câmera, imagem, lousa que aproxime mais os alunos da sala de aula). Então esses recursos metodológicos que não temos acabam atrapalhando. Eu tenho esse espaço só para aulas em casa e isso me ajuda muito. Mas ainda é um desafio levar totalmente a ludicidade para o ensino remoto, mas sigo tentando ao máximo.

Ricardo nos chama a atenção para o fato de que a ausência de recursos tecnológicos e de espaços adequados para as aulas online se configuram como um empecilho para o trabalho com a ludicidade. A fala de Ricardo nos remete aos estudos de Cordeiro (2020) e Hodges et al. (2020), ao destacarem a importância do uso de ferramentas remotas com parâmetros de qualidade, para que estas possam ter uma maior eficácia. Nosso colaborador pontua que, infelizmente, muitos docentes não conseguem oferecer esse parâmetro de qualidade, mas que apesar das dificuldades ele continua tentando ao máximo utilizar o lúdico em suas aulas. Percebemos, assim, o compromisso e a motivação do professor em superar os desafios, para que seus alunos tenham aulas mais lúdicas. Sobre os aspectos tecnológicos, Cícero e Ricardo evidenciam outros desafios:

\section{Excerto 04 - Professor Cícero}

Também vejo a parte tecnológica como desafio, porque não sou expert nessa área, e isso dificulta um pouco. Às vezes quero fazer um trabalho bom, algo que fique legal, mas para isso é necessário saber dos recursos, por exemplo, saber inserir um vídeo em uma apresentação do Power Point foi algo que eu aprendi nesse período de aulas remotas. Então, por não utilizar antes, foi algo em que eu senti dificuldade, mas estou sanando com a prática nas aulas remotas.

\section{Excerto 05 - Professor Ricardo}

/.../ A palavra "remoto" dá uma ideia de distância, eu tive que me reinventar em vários aspectos, com relação a minha timidez, na minha forma de me expressar com os alunos.

Joye et al. (2020) ressaltam que a atual pandemia desnudou a falta de formação docente referente ao uso de tecnologias digitais e, nos excertos 04 e 05, os professores Cícero e Ricardo nos provocam a pensar sobre esse aspecto. Cícero menciona, por exemplo, que inserir vídeo em uma apresentação e slides era algo que não fazia parte das suas atividades pedagógicas e, por isso, dificultava seu trabalho. Ricardo, além de textualizar que precisou reinventar a forma de se expressar com os alunos por meio de tecnologias, destaca o fator da timidez diante das câmeras. Nossos colaboradores demonstram que a utilização de recursos tecnológicos e a intimidade com uso da câmera não foram saberes construídos durante sua formação inicial ou continuada. Para tanto, eles tiveram que lidar com algo novo, o que se configurou como um desafio para a efetivação do trabalho.

Assim, a ausência de saberes para o trabalho online afeta a utilização do lúdico, descrita pelos docentes como algo difícil e complicado de ser concretizado no ensino remoto: 
Volume 16 - Número 1 - jan/jul de 2021

\section{Excerto 06 - Professor Cícero}

No ensino remoto é um pouco mais difícil utilizar essa questão da ludicidade, porque temos que seguir um padrão, como citei antes, no caso da plataforma em que não temos muita liberdade e utilizar outras formas de atividades além do texto, mas quando estou preparando a aula, que é o meu momento de interação com os alunos, eu procuro sempre fazer o meu melhor. [grifo nosso]

\section{Excerto 07 - Professor Ricardo}

O recurso lúdico no âmbito virtual está sendo complicado para mim, porque no ensino presencial os alunos aprendem juntos, existe uma tela enorme na frente dele, ele vê os vídeos, áudios de nativos em tempo real, há mais possibilidade de trabalhar o vocabulário e pronúncia de maneira super explicada, até que não haja mais dúvidas. Eu gosto muito de trabalhar com repetição, então no ensino presencial é mais fácil e mais completo, já que todos me acompanham ao mesmo tempo. [...] No ensino presencial temos mais recursos disponíveis. Já no ensino remoto, temos menos opções de ludicidade. [grifo nosso].

A partir da fala dos professores, percebemos que, ao discutir sobre o lúdico, eles tendem a comparar a utilização do lúdico no ensino presencial e no ensino remoto. Isso acontece, acreditamos, devido ao fato de que o trabalho com a ludicidade na modalidade presencial é o que eles conhecem e dominam. De acordo com os colaboradores, é difícil utilizar o lúdico de forma remota, uma vez que, como descreve Cícero, eles têm que seguir um padrão no uso da plataforma digital (Google Classroom), o que limita suas possibilidades e liberdade. Nos chama a atenção o tom de obrigatoriedade presente na fala de Cícero, embora o padrão mencionado seja algo que eles tenham que seguir, acreditamos que por ser algo novo, também seja difícil para o professor encontrar formas de ampliar o padrão estabelecido.

No excerto 07, Ricardo afirma que no ensino remoto há menos opções de recursos disponíveis para trabalhar com a ludicidade, reforçando a limitação descrita por Cícero. Além disso, Ricardo compreende que no ensino presencial "os alunos aprendem juntos" e todos "acompanham ao mesmo tempo", o que, para o professor, não acontece em uma sala virtual, dificultando a criação de um espaço lúdico. Ricardo traz uma reflexão significativa para o trabalho com a ludicidade no ensino remoto, que é a interação dos alunos entre eles e com o professor. Em uma sala virtual, com as câmeras e os microfones dos alunos muitas vezes desligados, a interação entre todos, para Ricardo, é difícil. Com as câmeras desligadas, por exemplo, o professor não consegue olhar para os alunos e, talvez, perceber se eles estão acompanhando sua explicação, se estão engajados na atividade ou até mesmo se, de fato, estão presentes na aula.

Observamos, até aqui, que ambos os colaboradores relatam os desafios enfrentados e pontuam um movimento de tentativas de superação das adversidades, de busca por darem o melhor de si: "sigo tentando ao máximo" (excerto 03), "senti dificuldade, mas estou sanando" (excerto 04), "tive que me reinventar" (excerto 05) e "eu procuro sempre fazer o meu melhor" (excerto 06). Percebemos, assim, que a busca por encontrar novas formas de ensinar no contexto remoto também é interpretada pelos professores como um movimento de aprendizagem.

Nessa perspectiva, apresentamos a seguir como os nossos colaboradores compreendem as aprendizagens advindas do ensino remoto emergencial.

\subsection{As aprendizagens durante o ensino remoto}

Junto com o ensino remoto surge a demanda por novos saberes no contexto da educação, em especial, saberes sobre a utilização de recursos tecnológicos. Entendemos que parte dos professores que atuavam no ensino presencial não utilizavam muitos recursos tecnológicos em 
sala de aula e, diante do contexto atual de pandemia, tiveram que se reinventar, como veremos nos excertos a seguir:

\section{Excerto 08 - Professor Cícero}

Apesar de ser tudo novo para mim, nessa área tecnológica que eu não tinha muito contato antes, está sendo maravilhoso descobrir um novo mundo e uma nova forma de trabalhar. Uma nova forma de estar perto mesmo distante através da tecnologia, está sendo muito bacana e um novo aprendizado. $\mathrm{O}$ interessante é que os próprios alunos têm me ajudado muito na questão do ensino remoto, com a tecnologia. Está sendo bacana descobrir esse mundo tecnológico que antes eu não tinha tanto acesso, e hoje estou tendo uma boa performance. [grifo nosso].

\section{Excerto 09 - Professor Ricardo}

Eu percebi também que nessa modalidade remota eu tive que me atualizar, de modo que busquei passar o conteúdo de uma maneira diferente, e isso me fez me atualizar mais e estudar novamente sobre o que seria visto na sala. /.../ Então, no início eu me senti um professor qualquer, igual aqueles que não tem o planejamento adequado. Então eu busquei inovações e atualizações e isso tem me ajudado muito. [grifo nosso].

Hodges et al. (2020) registra sobre a impossibilidade de todos os membros do corpo docente se tornarem, de maneira rápida, especialistas no ensino e aprendizagem online. Cícero e Ricardo descrevem que não tinham muita experiência com a tecnologia para fins educacionais e, por isso, o ensino remoto é um mundo novo para eles. Diante de um contexto novo, Ricardo afirma que no início se sentia "um professor qualquer, igual aqueles que não tem o planejamento adequado" e Cícero relata que os alunos têm ajudado com o manejo da tecnologia. A reflexão dos professores nos chama a atenção para a sensibilidade diante dos erros e acertos, pois eles fazem parte do processo de aprendizagem e, também, para a necessidade de um espaço colaborativo, onde todos se ajudam.

Os professores destacam, ainda, que no ensino remoto eles descobriram novas e diferentes formas de trabalhar, que antes não tinham acesso. Eles precisam estar abertos a novas aprendizagens, estudar novamente, buscar inovações e atualizações para, assim, conseguirem efetivar suas ações remotamente. Nesse sentido, percebemos Cícero e Ricardo como professores ativos em busca de novos saberes, professores que não se acomodaram diante dos desafios. Eles reconhecem que o processo de descobertas tem ajudado muito e que hoje, meses depois do início das aulas remotas, eles apresentam uma boa performance com as tecnologias.

Além disso, Cícero indica satisfação no processo de descobertas, é algo que ele considera "bacana". Cícero também nos apresenta a sala de aula remota como "uma nova forma de estar perto mesmo distante", ou seja, uma forma de aproximar alunos e professores e de fazer educação em tempos tão difíceis.

$\mathrm{Na}$ seara das discussões sobre aprendizagens no trabalho remoto com a ludicidade, questionamos os professores sobre as maiores aprendizagens advindas dessa experiência. Vejamos suas respostas:

\section{Excerto 10 - Professor Cícero}

As principais aprendizagens advindas dessa experiência foram sobre a interação com temas que eles gostam, como por exemplo, os jogos, como também sobre aprender a utilizar essa parte tecnológica, vejo como algo excepcional. Aprendi muito e gostei bastante, com certeza vai ser algo que eu vou utilizar sempre. Estão falando sobre a possibilidade do ensino híbrido, então se fizerem isso vai ser muito bom. [grifo nosso].

\section{Excerto 11 - Professor Ricardo}

$\mathrm{Eu}$ acho que uma experiência foi o recurso da câmera, vejo como algo que eu possa usar sem problema futuramente, algo que eu poderei para incluir dentro das minhas habilidades, de modo que eu posso 
Volume 16 - Número 1 - jan/jul de 2021

gravar a aula e enviar para os alunos no caso de dúvida. /.../ Então esse é um aspecto positivo para ampliar o meu método, ou até mesmo criar um canal no YouTube, há uma possibilidade futura, eu venho pensando bastante em montar um estúdio, equipar e começar a montar as aulas para que eu possa passar para os alunos que faltarem, como também ajudar outros alunos. [grifo nosso].

Os colaboradores marcam como principais aprendizagens a utilização da parte tecnológica, o uso de temas que os alunos gostam, como jogos, e o domínio da câmera para a gravação de aulas. Recuperamos que o professor Ricardo (excerto 05) relatava sua timidez diante da câmera e, talvez, por isso a utilização desse recurso seja algo tão significativo para ele. Nessa discussão, compreendemos que algumas das lacunas na formação docente - referente ao uso de tecnologias digitais - conforme mencionado por Joye et al. (2020), vão sendo sanadas a partir de saberes construídos com a experiência no ensino remoto.

É importante destacar que ambos os professores compreendem os saberes construídos de forma positiva, na medida em que projetam sua utilização em espaços futuros. Cícero considera o uso de tecnologias excepcional, algo que ele pensa em utilizar sempre, seja no ensino híbrido ou no ensino presencial. Ricardo comenta sobre a possibilidade de criar um canal no Youtube para disponibilizar suas aulas para os alunos que, por algum motivo, necessitem faltar. A ideia de Ricardo é ajudar não apenas seus alunos, mas todos aqueles que ele conseguir alcançar com seu canal no Youtube.

Diante das projeções dos nossos colaboradores, entendemos que o ensino remoto, mesmo sendo algo com um início cheio de desafios, trouxe uma gama de novas possibilidades para Cícero e Ricardo. Nessa perspectiva, perguntamos os aspectos que os fortaleceram como professores, a partir da experiência no ensino remoto:

\section{Excerto 12 - Professor Cícero}

Alguns dos aspectos que me fortaleceu como professor foi ter um maior compromisso com meu trabalho, com meus alunos, e com o que eu faço de maneira geral. Eu vejo que verdadeiramente tem alunos que realmente tem sede de aprendizagem. E que buscam sempre estudar e aprender mais, independentemente do método de ensino utilizado. Isso é algo que eu vou levar para sempre [grifo nosso].

\section{Excerto 13 - Professor Ricardo}

$\mathrm{O}$ aspecto que me fortaleceu foi me inventar diante das dificuldades, quando achávamos que não teríamos condições. A palavra "remoto" dá uma ideia de distância, eu tive que me reinventar em vários aspectos, com relação a minha timidez, na minha forma de me expressar com os alunos, passei a ter um uma nova visão do mundo também. [grifo nosso].

A fala dos colaboradores reforça a discussão empreendida por Cordeiro $(2020$, p. 6) de que, diante do ensino remoto em tempos de pandemia, os professores necessitam "reaprender a ensinar e reaprender a aprender". Cícero pontua que perceber a sede de aprendizagem dos alunos, mesmo diante de um cenário de adversidades, foi algo que o fortaleceu como professor, despertando um maior compromisso com seu trabalho e com os alunos. Esse aprendizado é algo que ele vai "levar para sempre", o que demonstra as marcas positivas do ensino remoto, com saberes construídos para um uso emergencial e projetados para o futuro. Nessa perspectiva, Ricardo relata que foi necessário se reinventar diante das dificuldades e isso o fortaleceu, na medida em que passou a ter "uma nova visão de mundo", uma nova visão de ensinar.

Essas reflexões reforçam não apenas a riqueza das aprendizagens construídas por Cícero e Ricardo, mas, também, nosso entendimento de que muitas das formas de fazer educação utilizadas no ensino remoto, irão compor as práticas pedagógicas na modalidade presencial, fazendo parte do acervo de conhecimento dos professores e das suas identidades profissionais. 
Volume 16 - Número 1 - jan/jul de 2021

\section{Considerações finais}

No presente estudo apresentamos algumas reflexões sobre o trabalho de dois professores de língua inglesa durante o ensino remoto de emergência (decorrente da pandemia da COVID19), com foco na utilização do lúdico. Para tanto, objetivamos identificar os desafios e discutir as aprendizagens presentes na fala dos colaboradores, sobre a experiência da ludicidade no ensino remoto, isto é, realizamos uma leitura da maneira como os professores interpretam esses desafios e aprendizagens.

Identificamos vários desafios apresentados pelos nossos colaboradores no trabalho com a ludicidade no ensino remoto, quais sejam: a impossibilidade de alcançar a totalidade dos alunos, devido à falta ou à limitação de recursos tecnológicos; a ausência do contato direto com os estudantes, o que limita a compreensão de como o aluno está interagindo com a explicação do conteúdo; a falta de conhecimentos sobre o uso de tecnologias digitais e sobre o ensino online, o que demandou tempo para que os professores dominassem novos saberes, como a gravação de aulas; a diminuição das possibilidades de trabalho com o lúdico - jogos, por exemplo - no espaço da sala de aula e do ambiente virtual de aprendizagem. Os professores relatam não terem liberdade e não enxergarem muitas possibilidades de utilização do lúdico nesses espaços; e a ausência de recursos adequados disponíveis para o professor, como espaço, iluminação, câmera e lousa que aproxime mais os alunos, motivando sua participação e ampliando o desenvolvimento de atividades lúdicas.

Ressaltamos que, ao apresentarem esses desafios, os professores tendem a realizar uma comparação com o lúdico no ensino presencial, considerando que no trabalho presencial eles encontram mais possibilidades de exploração da ludicidade, tendo em vista que dominam os recursos desse contexto e conseguem efetivar uma participação maior dos alunos nas tarefas.

Ademais, mesmo diante desses desafios, os professores pontuaram que conseguem utilizar atividades lúdicas no ensino remoto, as quais promovem a criação de uma aula mais dinâmica e menos monótona. Além disso, Ricardo e Cícero destacam que o lúdico no ensino remoto chama a atenção dos alunos, promovendo maior interação e motivação e, por conseguinte, ajudando no processo de aprendizagem da língua inglesa.

Sobre as aprendizagens, a fala dos docentes indicam aprendizagens construídas a partir da experiência no ensino remoto, as quais se apresentam por meio de alguns aspectos, a saber: a capacidade de se reinventar diante das circunstâncias desafiadoras do ensino remoto; a possibilidade de estarem abertos a novas e diferentes formas de trabalhar; a construção de saberes relacionados ao uso de tecnologias digitais e ao ensino online. Para tanto, os professores buscaram estudar mais e, também, aprender com os alunos; a capacidade de vencer a timidez diante das câmeras, a ponto de projetar a criação de um canal no YouTube para compartilhar as aulas; e o desenvolvimento de um maior compromisso com o trabalho docente, diante do esforço dos alunos na busca por aprender.

Percebemos que a experiência no ensino remoto, mesmo tendo um início cheio de desafios, trouxe possibilidades de desenvolvimento para Ricardo e Cícero. Os docentes se apresentaram de maneira aberta para as novas aprendizagens e de forma ativa, pesquisando e buscando diferentes modos de inovar e levar o melhor para os alunos. Eles não se acomodaram ou desistiram, nos mostrando a capacidade do ser humano e do professor de se reinventar diante das dificuldades e das novas demandas da profissão.

Destacamos, igualmente, que os saberes construídos no ensino remoto foram significativos, a ponto de os professores não apenas utilizarem no momento em que estavam situados, mas projetarem em seu trabalho futuro, seja na modalidade remota, presencial ou híbrida. As experiências de Ricardo e Cícero nos mostram, portanto, que os desafios do ensino remoto podem se configurar como espaços de formação docente. 
Desse modo, ressaltamos a relevância pedagógica da pesquisa por contribuir com o fortalecimento do uso de tecnologias digitais na educação e com o trabalho docente na modalidade remota. Além disso, o estudo propicia novas reflexões a respeito da necessidade da utilização de recursos lúdicos no ensino remoto, como estratégia didática para a motivação e o engajamento dos alunos.

Com essas reflexões, o presente estudo aponta para a urgência na criação e implantação de políticas públicas que invistam na acessibilidade digital dos alunos e professores. A pesquisa também indica a necessidade de uma formação docente (inicial e continuada) que seja sensível às tecnologias digitais e ao ensino online, já que estes têm se mostrado como ferramentas não apenas emergenciais, mas essenciais para se fazer educação.

Por fim, como professoras de língua inglesa, destacamos que realizar este estudo foi um processo rico de aprendizagem sobre ludicidade no ensino remoto. Aprendemos, ainda, sobre a capacidade do professor de se reinventar e ressignificar seu trabalho diante das dificuldades, como ressaltado pelo colaborador Ricardo com uma fala que encerra esta narrativa: "Eu tive que me reinventar em vários aspectos ... passei a ter um uma nova visão do mundo" (Ricardo).

\section{Referências}

ARRUDA, E. P. Educação remota emergencial: elementos para políticas públicas na educação brasileira em tempos de Covid-19. Em Rede: Revista de Educação a Distância, Porto Alegre, v.7, n.1, p.257-275, 2020. Disponível em: $<$ https://www.aunirede.org.br/revista/index.php/emrede/article/view/621 $>$ Acesso em: 05 Nov. 2020.

BARBOSA, A. P. M. Ludoteca: um espaço lúdico. 39fls. 2010. Trabalho de Conclusão de Curso (Graduação em Pedagogia) - Universidade Estadual de Londrina, Londrina, 2010. Disponível em: $<$ http://www.uel.br/ceca/pedagogia/pages/arquivos/2010\%20ANA\%20PAULO $\% 20$ MONTO LEZI.pdf $>$ Acesso em: 14 Jul. 2017.

BASTOS, L. C.; SANTOS, W. S. A entrevista na pesquisa qualitativa: perspectivas em análise da narrativa e da interação. Rio de Janeiro: Quartet Editora, 2013.

BASTOS, R. L. G.; LIMA, S. C. Narrativas de aprendizagem de inglês em tempos de pandemia. In: OLIVEIRA, K.C. et al. (Orgs.). Reflexões sobre o ensino de línguas e literatura, formação docente e material didático. São Carlos: Pedro \& João Editores, 2020.

BRASIL. Parecer CNE/CP n $\mathbf{n}^{\mathbf{5}}$ /2020, aprovado em 28 de abril de 2020 - Reorganização do Calendário Escolar e da possibilidade de cômputo de atividades não presenciais para fins de cumprimento da carga horária mínima anual, em razão da Pandemia da COVID-19. Brasília, 2020.

Disponível

em:

$<$ http://portal.mec.gov.br/index.php?option $=$ com_docman\&view $=$ download\&alias $=145011$ pcp005-20\&category slug=marco-2020-pdf\&Itemid=30192> Acesso em: 08 Nov. 2020.

BRONCKART, J. P. Atividade de linguagem, textos e discursos: por um Interacionismo Sociodiscursivo. São Paulo: Educ, 2012 [1999].

CORDEIRO, K. M. A. O impacto da pandemia na educação: a utilização da tecnologia como ferramenta de ensino. 15fls. 2020. Trabalho de Conclusão de Curso (Graduação em Pedagogia) - Universidade Federal do Amazonas, Manaus, 2020. Disponível em: $<$ http://idaam.siteworks.com.br/jspui/handle/prefix/1157>. Acesso em: 06 Nov. 2020.

GARCIA, T. C. M. et al. Ensino remoto emergencial: proposta de design para organização de aulas. Natal: $\quad$ SEDIS/UFRN, 2020. Disponível em: 
$<$ https://repositorio.ufrn.br/bitstream/123456789/29767/1/ENSINO\%20REMOTO\%20EMER GENCIAL proposta de design organizacao aulas.pdf $>$. Acesso em: 09 Nov. 2020.

HODGES, C. et al. As diferenças entre o aprendizado online e o ensino remoto de emergência. Revista da Escola, Professor, Educação e Tecnologia, Recife, v. 2, 2020. Disponível em: $<$ https://escribo.com/revista/index.php/escola/article/view/17>. Acesso em: 05 Nov. 2020.

JOYE, C. R. et al. Educação a Distância ou Atividade Educacional Remota Emergencial: em busca do elo perdido da educação escolar em tempos de COVID-19. Research, Society and Development, São Paulo, v.9, n.7, 2020. Disponível em: $<$ https://rsdjournal.org/index.php/rsd/article/view/4299/3757>. Acesso em: 11 Nov. de 2020. MICHELON, D. A motivação na aprendizagem da língua inglesa. Revista Língua \& Literatura, Rio Grande do Sul, v.5, n.8, p.78-96, 2003. Disponível em:

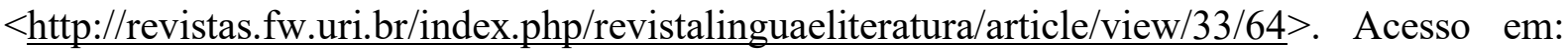
10 Ago. 2020.

MOITA LOPES, L. P. Da aplicação de linguística à linguística aplicada indisciplinar. In: PEREIRA, R. C.; ROCA, P. (Orgs.). Linguística aplicada: um caminho com diferentes acessos. São Paulo: Contexto, 2015.

NOGUEIRA, Z. P. Atividades lúdicas no ensino/aprendizagem de língua inglesa. Portal Diaa-dia Educação, p.967-4, $2008 . \quad$ Disponível em: $<$ http://www.gestaoescolar.diaadia.pr.gov.br/arquivos/File/producoes_pde/artigo_zelia_paiva nogueira.pdf $>$. Acesso em: 2 Set. 2020.

PESSOLANO, J.; DALLA CORTE, M. Uma interface entre cultura, motivação e ludicidade no ensino de línguas. Linguagens \& Cidadania, Santa Maria, v. 3, n. 2, 2001. Disponível em: $<$ https://periodicos.ufsm.br/LeC/article/viewFile/31512/17278 > . Acesso em: 12 Ago. 2020. ROLIM, A. A. M. et al. Uma leitura de Vygotsky sobre o brincar na aprendizagem e no desenvolvimento infantil. Revista Humanidades, Fortaleza, v. 23, n.2, p.176-180, 2008. Disponível em $<$ http://brincarbrincando.pbworks.com/f/brincar\%2B_vygotsky.pdf $>$. Acesso em: 25 Mai. 2020.

SANTANNA, A.; NASCIMENTO, P. R. A história do lúdico na educação The history of playful in education. Revemat: Revista Eletrônica de Educação Matemática, Florianópolis, v.6, n.2, p.19-36, 2011. Disponível em:< https://periodicos.ufsc.br/index.php/revemat/article/view/1981-1322.2011v6n2p19/21784>.

Acesso em: 07 Ago. 2017.

SANTOS, S. C. A importância do lúdico no processo de ensino aprendizagem. 50f. 2010. Trabalho de Conclusão de Curso (Especialização em gestão educacional). Universidade Federal de Santa Maria, Santa Maria, 2010. Disponível em: $<\underline{\text { http://repositorio.ufsm.br/bitstream/handle/1/393/Santos_Simone_Cardoso_dos.pdf?sequenc }}$ $\mathrm{e}=1>$. Acesso em: 11 Set. 2017.

SILVA, E. A.; FANTINELLI, N. C. C. O lúdico como possibilidade para a aprendizagem de crianças diagnosticadas com transtorno do déficit de atenção/hiperatividade (TDAH) certificado tutoria e o papel do tutor. In: POISSON EDITORA (Org.). Educação no Século XXI: Especial, Inclusiva. Minas Gerais: Poisson, 2019.

SILVA, E. H. B. et al. Pedagogia da pandemia: reflexões sobre a educação em tempos de isolamento social. Revista Latino-Americana de Estudos Científicos, Vitória, v.01, n.04, p.29-44, 2020. Disponível em: $<$ https://periodicos.ufes.br/ipa/article/view/31695 $>$. Acesso em: 10 Nov. 2020.

VALENTE, J. A. As tecnologias digitais e os diferentes letramentos. Porto Alegre: Pátio, 2007.

ZANELLA, L. C. H. Metodologia da pesquisa. Florianópolis: SEAD/UFSC, 2013. Disponível em: $<$ http://arquivos.eadadm.ufsc.br/EaDADM/UAB_2014_2/Modulo_1/Metodologia/materi 
al_didatico/Livro\%20texto\%20Metodologia\%20da\%20Pesquisa.pdf $>$. Acesso em: 15 Set. 2020.

Submetido em 29/03/2021 Aceito em 20/08/2021 